\title{
Thermal, spectroscopic and in vitro biological studies of the lanthanum complex of naproxen
}

\author{
D.A. Gálico ${ }^{\mathrm{a}, \mathrm{b}}$, T.F.C. Fraga-Silva ${ }^{\mathrm{c}}$, J. Venturini ${ }^{\mathrm{d}}$, G. Bannach ${ }^{\mathrm{b}, *}$ \\ a UNICAMP-Univ de Campinas, Instituto de química, CEP 13083-970, Brazil \\ b UNESP-Univ Estadual Paulista, Faculdade de Ciências, Departamento de Química, Bauru, SP CEP 17033-260, Brazil \\ ' UNESP-Univ Estadual Paulista, Instituto de biociências, Botucatu, SP CEP 18618-970, Brazil \\ d UNESP-Univ Estadual Paulista, Faculdade de Ciências, Departamento de Ciências Biológicas, Bauru, SP CEP 17033-260, Brazil
}

\section{A R T I C L E I N F O}

Article history:

Received 3 August 2016

Received in revised form 17 October 2016

Accepted 18 October 2016

Available online 19 October 2016

\section{Keywords:}

Naproxen

Thermal behavior

Spectroscopic studies

Polymorphism

Lanthanum

In vitro biological studies

\begin{abstract}
A B S T R A C T
Solid-state [ $\mathrm{La}(\mathrm{Nap})_{3}\left(\mathrm{H}_{2} \mathrm{O}\right)$ ], in which Nap is naproxen have been synthesized. Thermogravimetry (TG), differential thermal analysis (DTA), differential scanning calorimetry (DSC), powder X-ray diffractometry (XRD), elemental analysis, complexometric titration, middle (MIR) and near (NIR) infrared region spectroscopy were used to characterize this compound and confirm the proposed stoichiometry. The experimental results provided information concerning the chemical composition, dehydration, coordination modes of the ligand, crystallinity of the sample, thermal behavior, thermal decomposition and polymorphism. Theoretical calculations helped in the assignment of the MIR vibrational bands and in the understanding of the coordination mode of the ligands. Cyclic DSC and XRD in different temperatures demonstrated that the complex presents five temperature dependent polymorphic forms. MIR spectroscopy suggest that the naproxen coordinates through the carboxylate group as a chelating ligand. $\left[\mathrm{La}(\mathrm{Nap})_{3}\left(\mathrm{H}_{2} \mathrm{O}\right)\right]$ showed lower cell cytotoxicity in comparison to naproxen. The compound increased the production of pro-inflammatory metabolites, such as TNF- $\alpha$, IL- $1 \beta$ and $\mathrm{H}_{2} \mathrm{O}_{2}$, and decreased an IL-8 level, that interferes in the trafficking of inflammatory cells.
\end{abstract}

(C) 2016 Elsevier B.V. All rights reserved.

\section{Introduction}

Lanthanides complexes with non-steroidal anti-inflammatory has been synthesized and studied by our group. Complexes with ketoprofen exhibit spectroscopic and biological properties which enable applications in biological and technological fields [1-4]. Complexes with ibuprofen, indomethacin and mefenamic acid has also been investigated by our group [5-7].

Naproxen (Nap, Fig. 1a), or (+)-(S)-2-(6-methoxynaphthalen2-yl)propanoic acid, is a NSAID that belongs to the class of 2-arylpropionic acids, which constitute a considerable group of pharmaceutical and commercial interest (Fig. 1a) [8]. Chen et al. [9] synthesized naproxen complexes with lanthanides (except gadolinium and lutetium), but no detailed thermal study of the complexes was been done in this study. The anti-inflammatory action studies for the neodymium complex were performed in vivo, without a cytotoxicity assay in human cells, which exhibits higher anti-inflammatory activity than naproxen.

\footnotetext{
* Corresponding author.

E-mail address: gilbert@fc.unesp.br (G. Bannach).
}

Thermal methods of analysis has been widely used in the coordination chemistry and in the pharmaceutical field to study solid state reactions [10], polymorphism [11], thermal stability [12], drug formulations [13], purity [14], reaction kinetics [15], evolved gas analysis by coupled TG-FTIR [16,17] and other properties of solid compounds used in pharmaceutical industry.

Thus, this work's purpose is to provide a detailed study of the thermal behavior of the lanthanum complex with naproxen, spectroscopic information in ultraviolet, visible, near and middle infrared regions and in vitro biological activity.

\section{Experimental}

\subsection{Synthesis of the complex}

Naproxen (acid form) with $\geq 98 \%$ purity was purchased from Aldrich and was used without further purification. An aqueous solution of naproxen sodium salt $\left(0.1 \mathrm{~mol} \mathrm{~L}^{-1}\right)$ was prepared by neutralizing an aqueous naproxen suspension with a $0.1 \mathrm{~mol} \mathrm{~L}^{-1}$ sodium hydroxide solution and the $\mathrm{pH}$ was adjusted to 8.0. Lanthanum chloride was prepared from the corresponding metal oxide ( $\mathrm{La}_{2} \mathrm{O}_{3}$, Aldrich, $\geq 99.9 \%$ purity) by the treatment with concentrated hydrochloric acid. The resulting solutions were evaporated to near 
(a)

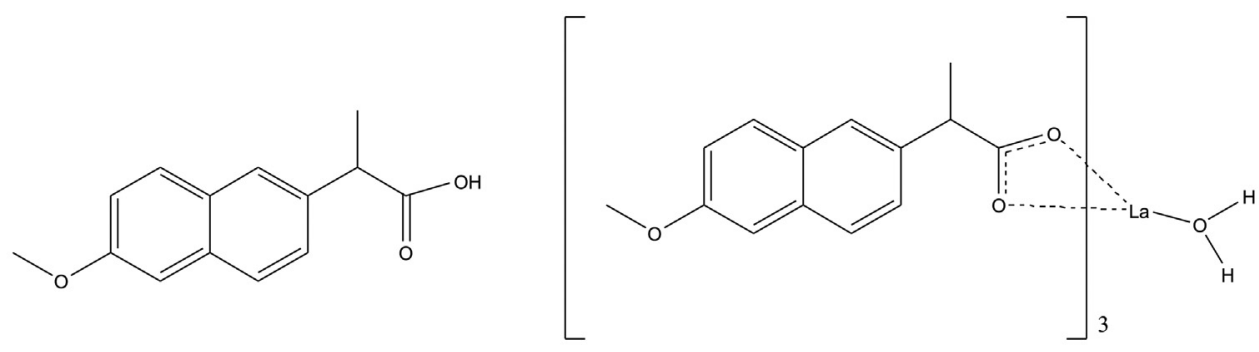

Fig. 1. Structural formula of (a) naproxen and (b) $\left[\mathrm{La}(\operatorname{nap})_{3}\left(\mathrm{H}_{2} \mathrm{O}\right)\right]$.

dryness by heating, the remaining residue were redissolved in distilled water and the solution were once again evaporated to near dryness to eliminate the excess of hydrochloric acid. The residue was finally dissolved in distilled water, transferred to a volumetric flask and diluted in order to obtain ca. $0.1 \mathrm{~mol} \mathrm{~L}^{-1}$ solutions, whose pH's were adjusted to 5.0 by adding diluted sodium hydroxide or hydrochloric acid solutions.

The complex were prepared by adding, slowly and under continuous stirring the naproxen sodium salt to the lanthanum chloride solution until total precipitation of the complex. The precipitate was filtered through a Whatman no. 42 filter paper, washed with distilled water in order to eliminate the chloride ions and kept in a desiccator with anhydrous calcium chloride under reduced pressure.

\subsection{Characterizations}

Simultaneous thermogravimetry and differential thermal analysis (TG-DTA) curves were obtained with a SDT 2960 (TA Instruments) thermal analysis equipment, under the following experimental conditions: open $\alpha$-alumina crucibles, heating rate of $20^{\circ} \mathrm{C} \mathrm{min}^{-1}$, air atmosphere at a $100 \mathrm{ml} \mathrm{min}^{-1}$ flow and sample of $7.02 \mathrm{mg}$.

The metal contents were determined by complexometric titrations with standard EDTA solution using xylenol orange as indicator [18]. The contents of carbon and hydrogen were analyzed using a Perkin-Elmer 2400 series II analyzer.

The differential scanning calorimetry (DSC) curve of the complex was obtained on a Q-10 thermal analysis systems (TA Instruments) under the following experimental conditions: aluminum crucible with perforated cover, heating and cooling rate of $10^{\circ} \mathrm{C} \mathrm{min}^{-1}$, air atmosphere at $100 \mathrm{ml} \mathrm{min}^{-1}$ flow and sample of $2.92 \mathrm{mg}$.

X-ray powder diffractograms (XRD) were measured on a Shimadzu XRD-6000 X-ray diffractometer using $\mathrm{Cu} \mathrm{K} \alpha$ radiation $(\lambda=1.541 \AA$ ) and settings of $40 \mathrm{kV}$ and $30 \mathrm{~mA}$. The heating/cooling of the sample follow the rate of $5^{\circ} \mathrm{Cmin}^{-1}$ and the waiting time in each temperature before the measurement was $120 \mathrm{~s}$.

Middle infrared region (MIR) spectra were performed on a Nicolet iS10 FTIR spectrophotometer using an ATR accessory with Ge window within the $4000-600 \mathrm{~cm}^{-1}$ range. Near infrared spectra (NIR) were collected on a Thermo Scientific Antaris II spectrophotometer by reflectance within the $10000-4000 \mathrm{~cm}^{-1}$ range.

Diffuse reflectance (DR) spectra were acquired on a Varian Cary 5000 spectrophotometer within the $200-1000 \mathrm{~nm}$ range with spectral resolution of $0.5 \mathrm{~nm}$.

\subsection{In vitro biological studies}

\subsubsection{Peripheral blood mononuclear cells (PBMC)}

The sample included ten healthy subjects recruited from blood bank. The inclusion criterion was the signing of the Consent and
Informed. This study was approved by the Research Ethics Committee of the School of Sciences of UNESP Bauru. Written informed consent for participation and publication of data were obtained and signed by all participants. Peripheral blood was obtained from healthy subjects by venous puncture and placed into $10.0 \mathrm{ml}$ sterile tubes containing $20.0 \mathrm{U} / \mathrm{mL}$ heparin. Mononuclear cells were recovered by density gradient separation using Histopaque ${ }^{\circledR}$ 1077 (Sigma-Aldrich, St. Louis, MO, USA) and, afterwards, washed with RPMI 1640 culture medium (Nutricell, Campinas-SP, Brazil) for $10 \mathrm{~min}$ at $1500 \mathrm{rpm}$. After this procedure, the cells were resuspended in RPMI 1640 culture medium supplemented with $20 \%$ autologous serum and streptomycin/penicillin (complete medium). The cell count was performed using Turk's solution and the viability of PBMC was assessed by Trypan Blue $(0.1 \%)$ uptake. The cell concentration was adjusted to $10^{6}$ cells $\mathrm{mL}^{-1}$.

\subsubsection{Cytotoxicity assay}

The MTT (3-(4,5-dimetietiazol-2yl)-2,5-diphenyltetrazolium bromide) is a water soluble salt. The same is reacted with mitochondrial dehydrogenases present only in metabolically active cells, i.e., living cells resulting in the production of formazan crystals in purple, water insoluble [19]. This salt is therefore used to determine cell viability. The compounds were dissolved in serial 2-fold dilutions in $100 \%$ dimethyl sulfoxide (DMSO) and were prepared in a range of concentration from $50.0 \mathrm{mg} \mathrm{mL}^{-1}$ to $1.56 \mathrm{mg} \mathrm{mL}^{-1}$. PBMC $\left(10^{6}\right.$ cells $\left.\mathrm{mL}^{-1}\right)$ were seed into 96 well culture plates and stimulated with $1 \mu \mathrm{l}$ of each Nap or La-Nap range. The cells were incubated for $96 \mathrm{~h}$ at $37^{\circ} \mathrm{C}$ in $5 \% \mathrm{CO}_{2}$. After incubation, the culture plate was centrifuged for $5 \mathrm{~min}$ at $1500 \mathrm{rpm}$. The supernatant was discarded and the cells resuspended in complete medium containing MTT $\left(5 \mathrm{mg} \mathrm{mL}^{-1}\right)$. The plate was incubated for $2 \mathrm{~h}$ at $37^{\circ} \mathrm{C}$ in $5 \% \mathrm{CO}_{2}$ and after this period, centrifuged for $5 \mathrm{~min}$ at $1500 \mathrm{rpm}$. The supernatant was removed and the cells were resuspended in $100 \mu \mathrm{l}$ of dimethyl sulfoxide (DMSO) per well. After $5 \mathrm{~min}$, the plate was read in an ELISA reader at $540 \mathrm{~nm}$. The cytotoxicity index (IC) was obtained from the ratio of the test culture stimulated by the Nap or La-Nap and a control culture containing only cells stimulates with $1 \mu$ l of DMSO. The values lower than the values obtained in control cultures was considered cytotoxic and the values higher than the values obtained in the control culture was considered no citotoxic.

\subsubsection{Monocyte cell culture}

Mononuclear cells were obtained as described in PBMC item. To obtain human monocytes, PBMC were counted with phenol red solution $(0.02 \%)$ and the concentration was adjusted to $1 \times 10^{6}$ cells $\mathrm{mL}^{-1}$. Cells were seeded in 96-well culture plate and incubated for $1 \mathrm{~h}$ at $37{ }^{\circ} \mathrm{C}$ and $5 \% \mathrm{CO}_{2}$ for adhesion. After this period, the supernatant was removed and adhered cells were resuspended in complete medium. To evaluate the influence of compounds in 


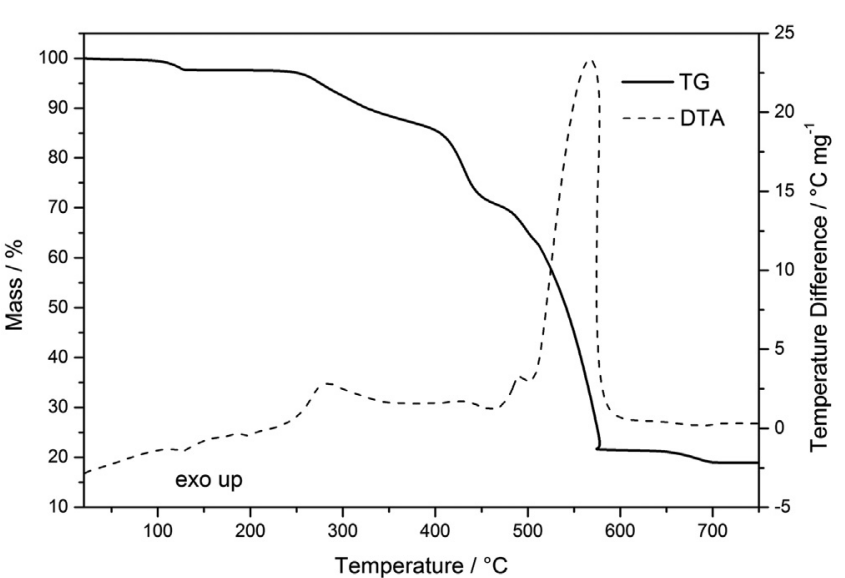

Fig. 2. TG-DTA curves for $\left[\mathrm{La}(\mathrm{nap})_{3}\left(\mathrm{H}_{2} \mathrm{O}\right)\right](\mathrm{m}=7.02 \mathrm{mg})$.

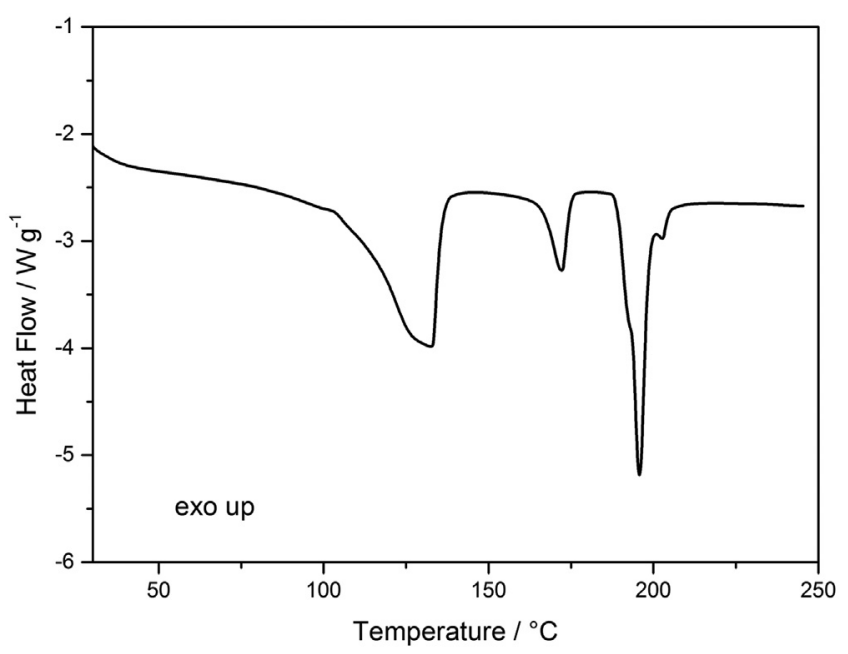

Fig. 3. DSC curve for $\left[\mathrm{La}(\mathrm{nap})_{3}\left(\mathrm{H}_{2} \mathrm{O}\right)\right](\mathrm{m}=2.92 \mathrm{mg})$.

an inflammatory microenvironment, monocytes were submitted to four treatments:

1) $1 \mu \mathrm{l}$ of DMSO (negative internal control);

2) lipopolysaccharide-LPS, $10.0 \mathrm{mg} \mathrm{mL}^{-1}$ (positive internal control);

3) simultaneous stimulation with LPS and $1 \mu$ l of Nap (50.0 $\mathrm{mg} \mathrm{mL}^{-1}$ ); and

4) simultaneous stimulation with LPS and $1 \mu \mathrm{l}$ of La-Nap (61.4 $\left.\mathrm{mg} \mathrm{mL}^{-1}\right)$.

The cells were incubated at $37^{\circ} \mathrm{C}$ and $5 \% \mathrm{CO}_{2}$. After $24 \mathrm{~h}$, the supernatants were collected for cytokine quantification and the adherent cells were submitted to the determination of hydrogen peroxide $\left(\mathrm{H}_{2} \mathrm{O}_{2}\right)$ release.

\subsubsection{Production of hydrogen peroxide $\left(\mathrm{H}_{2} \mathrm{O}_{2}\right)$}

At the end of monocyte culture incubation, the supernatant was removed and the cells were incubated with phenol red solution [dextrose (Sigma), phenol red (Sigma), horseradish peroxidase type II (Sigma)] and plated at $37^{\circ} \mathrm{C}$ in $5 \% \mathrm{CO}_{2}$ for $2 \mathrm{~h}$ according to the methods of Russo et al. [20]. The reaction was stopped with the addition of $1 \mathrm{~N} \mathrm{NaOH}$ and the $\mathrm{H}_{2} \mathrm{O}_{2}$ concentration was determined using an ELISA microreader (EL800, BIO-TEK Instruments, INC). The concentration was calculated using analytical curve $(0.5-8.0 \mathrm{nM}$ $\mathrm{H}_{2} \mathrm{O}_{2}$ ).

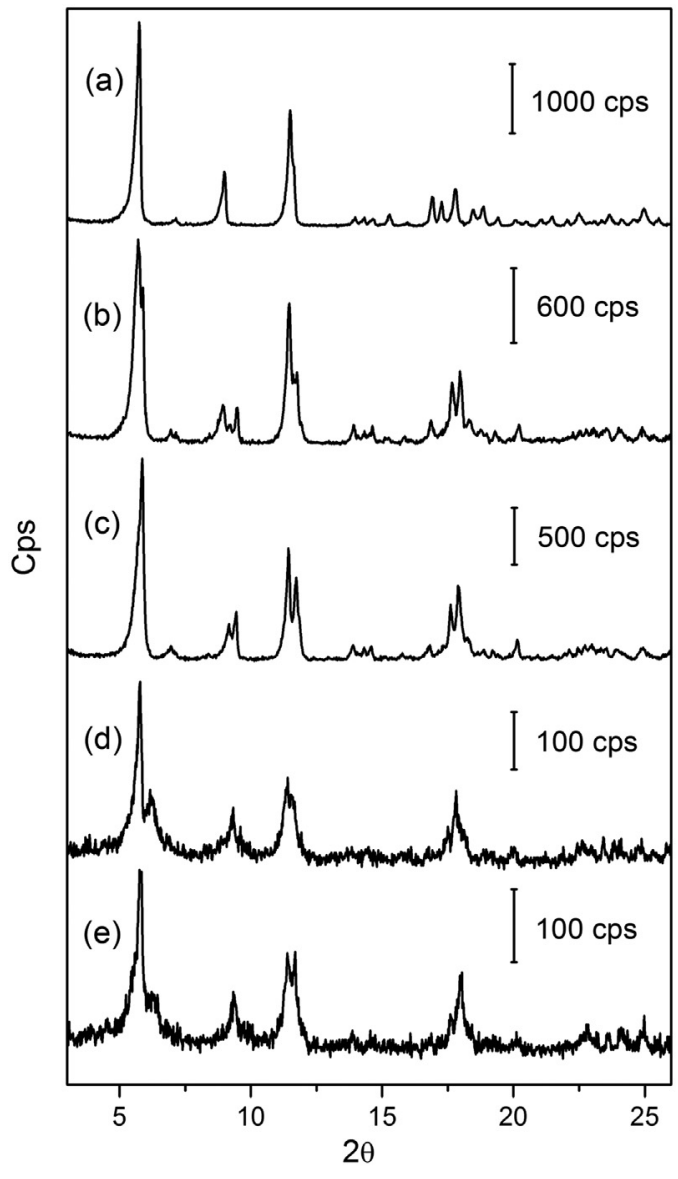

Fig. 4. XRD diffractograms for $\left[\mathrm{La}(\mathrm{nap})_{3}\left(\mathrm{H}_{2} \mathrm{O}\right)\right]$ obtained at (a) room temperature, (b) $138^{\circ} \mathrm{C}$, (c) $176^{\circ} \mathrm{C}$, (d) $197^{\circ} \mathrm{C}$ and (e) $205^{\circ} \mathrm{C}$ (after cooling).

\subsubsection{Quantification of cytokines}

The levels of interleukin-8 (IL-8), interleukin 1 beta (IL-1 $\beta$ ), interleukin 6(IL-6), interleukin 10 (IL-10), interleukin 12 (IL-12p70) and tumor necrosis factor alpha (TNF- $\alpha$ ) were determined by FACS (fluorescence-activated cell sorting) using BD cytometric bead array (CBA-BD Biosciences, CA, USA).

\subsubsection{Statistical analysis}

To test for the normality of data, results were analyzed by Shapiro-Wilk's test. Comparison between Nap and each compound was made by Wilcoxon test to non-parametric samples and made by Paired $t$-test to parametric samples. Values of $\mathrm{p}<0.05$ were considered statistically significant, that corresponds to $95 \%$ of confidence level. The GraphPad Prism v5.0 Statistical Guide (2007, GraphPad Software Inc., USA) for Windows was used to analyze data and create graphs.

\section{Results and discussion}

\subsection{Characterization and thermal study}

The elemental analysis, complexometric titration and thermogravimetric results are shown in Table 1 . These data permitted to establish the stoichiometry of the complex, which is in agreement with the formula $\left[\mathrm{La}(\mathrm{Nap})_{3}\left(\mathrm{H}_{2} \mathrm{O}\right)\right]$ (Fig. 1b). No single crystals where obtained for the complex; therefore, theoretical calculations have been used to understand the geometry and the coordination polyhedron of the complex. The computational strategy was detailed in the Supplementary material. The optimized structure for the complex is shown in Fig. S1 (see Supplementary material), while the 
Table 1

Analytical data of $\left[\mathrm{La}(\mathrm{Nap})_{3}\left(\mathrm{H}_{2} \mathrm{O}\right)\right]$ complex.

\begin{tabular}{|c|c|c|c|c|c|c|c|c|c|c|c|c|c|}
\hline \multicolumn{2}{|l|}{$C(\%)$} & \multicolumn{2}{|l|}{$\mathrm{H}(\%)$} & \multicolumn{3}{|c|}{ Metal (\%) } & \multicolumn{2}{|c|}{$\Delta_{\text {Ligand }}(\%)$} & \multicolumn{2}{|c|}{ Water (\%) } & \multicolumn{3}{|c|}{ Final Residue (\%) } \\
\hline Calc. & Exp. & Calc. & Exp. & Calc. & TG & $\overline{\text { EDTA }}$ & Calc. & TG & Calc. & TG & Calc. & TG & Oxide \\
\hline 59.66 & 59.25 & 4.89 & 4.97 & 16.44 & 16.15 & 16.49 & 78.59 & 78.70 & 2.13 & 2.35 & 19.28 & 18.95 & $\mathrm{La}_{2} \mathrm{O}_{3}$ \\
\hline
\end{tabular}

Cartesian coordinates, bond distances and other geometry information are listed in Table S1 (see Supplementary material). The coordination polyhedral obtained from the theoretical calculations is shown in Fig. S2 (see Supplementary material), the ligands are arranged around the ion with a trigonal prism geometry, distorted by the presence of the coordinated water molecule.

The simultaneous TG-DTA curve of the complex is shown in Fig. 2 and the details of the thermal events (mass losses, temperature intervals and peak temperatures) are described in Table 2. The TG curves exhibit mass losses in five steps and their corresponding thermal events in the DTA.

The first mass loss occurs in a single step between 30 and $135^{\circ} \mathrm{C}$ due to the dehydration of the complex with a correspondent endothermic peak at $127^{\circ} \mathrm{C}$ in the DTA curve. The TG curves show that the anhydrous complex is stable up to $227^{\circ} \mathrm{C}$ and after the dehydration, the mass losses observed for the compound are due to their thermal decompositions, which take place in consecutive and/or overlapping steps.

The second and third mass loss of the compound are assigned to the ligand decomposition whereas the fourth mass loss is assigned to the oxidation of the remaining organic matter, which is confirmed by the intense exothermic peak at $567^{\circ} \mathrm{C}$. The fifth mass loss
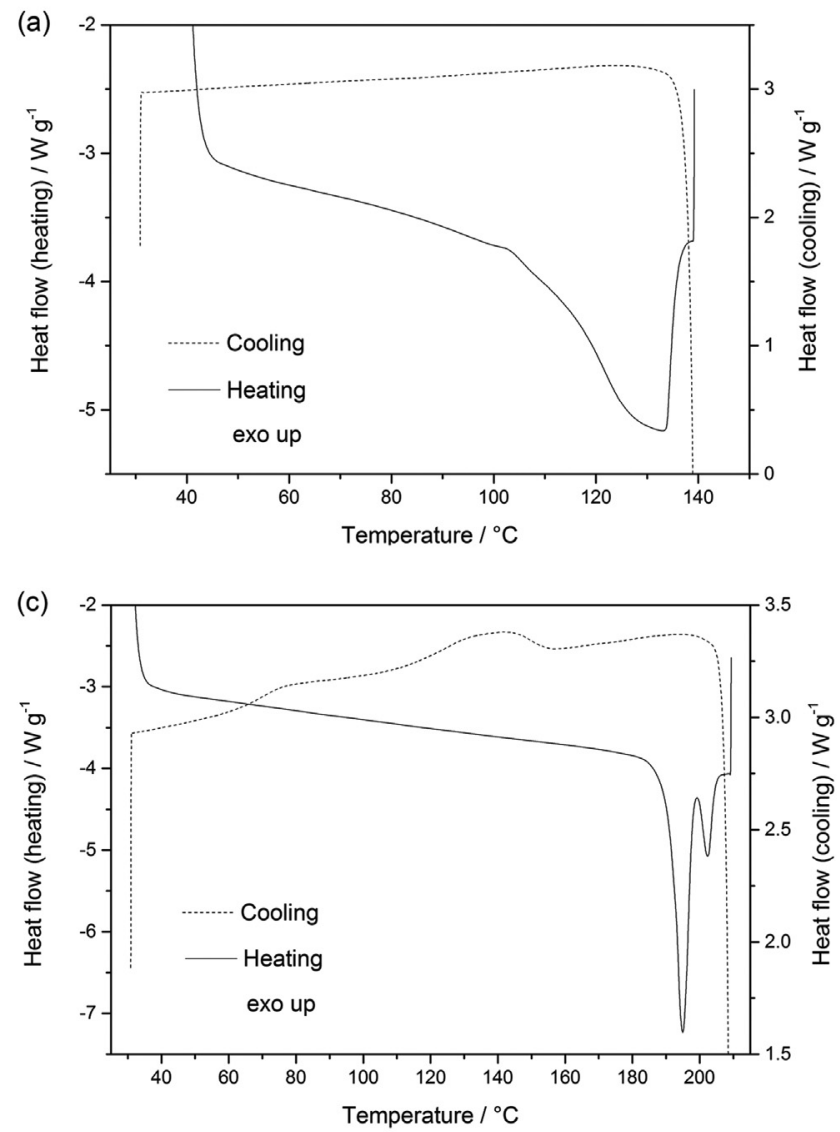

is related to the lanthanum dioxycarbonate intermediate decomposition to lanthanum oxide [21], according to the reaction:

$\mathrm{La}_{2} \mathrm{O}_{2} \mathrm{CO}_{3(\mathrm{~s})} \rightarrow \mathrm{La}_{2} \mathrm{O}_{3(\mathrm{~s})}+\mathrm{CO}_{2(\mathrm{~g})}$

The final residue of thermal decomposition for the complex is $\mathrm{La}_{2} \mathrm{O}_{3}$, as proven by X-ray powder diffractometry.

The DSC curve of the complex was shown in Fig. 3 and three main events are seen. The first is related to the dehydration of the compound (endothermic peak at $130^{\circ} \mathrm{C}$ ) with an $\Delta H_{\text {dehydration }}=41.88 \mathrm{~kJ} \mathrm{~mol}^{-1}$. The second event at $171^{\circ} \mathrm{C}$ (endothermic peak) and the third, which is divided in two overlapped peaks (endothermic peaks at 195 and $202^{\circ} \mathrm{C}$ ), occurs without mass loss in the TG curve. For a better understanding of these events, a cyclic DSC curve was been performed (Fig. 5) which was correlated with X-ray powder diffractograms in some interest temperature (Fig. 4).

The X-ray powder diffractogram obtained at room temperature (Fig. 4a) showed that the complex were obtained with a certain crystallinity degree. The most intense peaks appears at $2 \theta=5.7,8.9$, 11.5, 16.9, 17.2 and 17.8.

The cyclic DSC provides information about the reversibility of the thermal events. In the first heating/cooling cycle (Fig. 5a), it is possible to see the dehydration process, reported above; no ther-
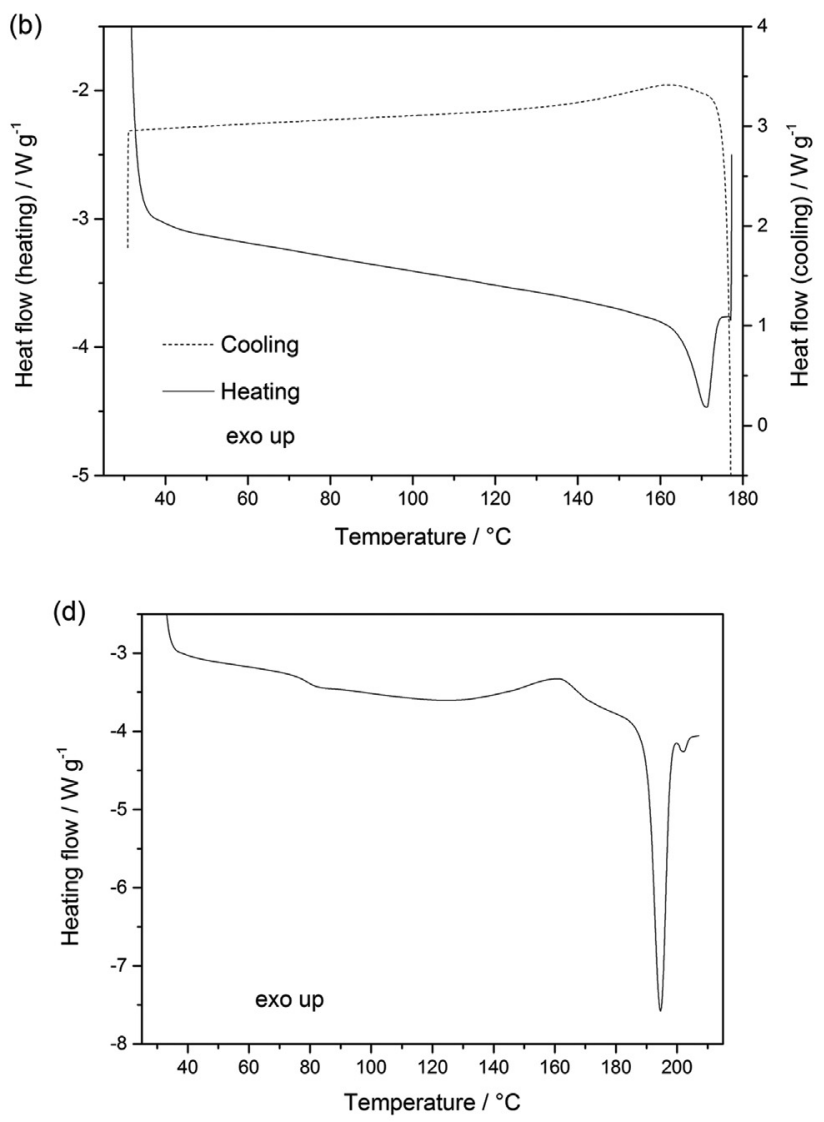

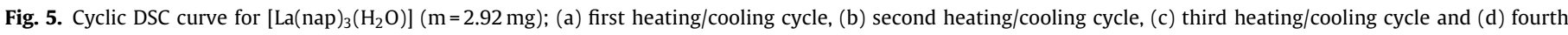
heating cycle. 
Table 2

Thermal events of the $\left[\mathrm{La}(\mathrm{Nap})_{3}\left(\mathrm{H}_{2} \mathrm{O}\right)\right]$ complex.

\begin{tabular}{|c|c|c|c|c|c|c|}
\hline & & \multicolumn{5}{|l|}{ Step } \\
\hline & & First & Second & Third & Fourth & Fifty \\
\hline \multirow{3}{*}[\mathrm{La}(\mathrm{Nap})_{3}(\mathrm{H}_{2}\mathrm{O})]{} & $\theta\left({ }^{\circ} \mathrm{C}\right)$ & $30-135$ & $227-365$ & $365-465$ & $465-584$ & $584-705$ \\
\hline & loss (\%) & 2.35 & 9.88 & 16.93 & 49.33 & 2.56 \\
\hline & peak $\left({ }^{\circ} \mathrm{C}\right)$ & 127 (endo) & 279 (exo) & - & 489 and 567 (exo) & 661-710 (endoterm) \\
\hline
\end{tabular}

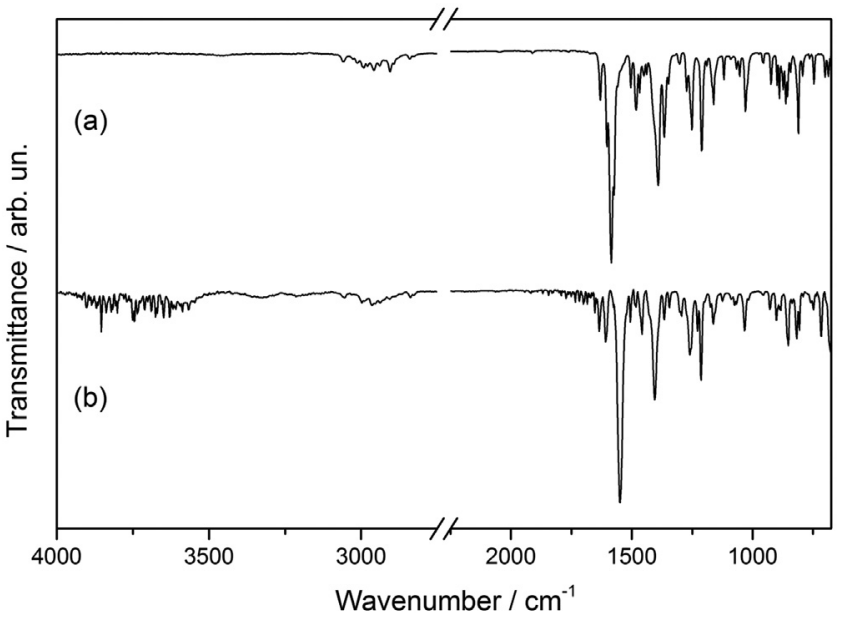

Fig. 6. MIR spectra of (a) sodium salt of naproxen, (b) $\left[\mathrm{La}(\mathrm{nap})_{3}\left(\mathrm{H}_{2} \mathrm{O}\right)\right]$ (experimental) and (c) $\left[\mathrm{La}(\text { nap })_{3}\left(\mathrm{H}_{2} \mathrm{O}\right)\right]$ (theoretical).

mal event was seen in the cooling indicating that the change in crystallinity after the dehydration process (Fig. 4a-b) occurs only by the loss of the coordinated water molecule. In the second heating cycle (Fig. 5b), the endothermic peak at $171^{\circ} \mathrm{C}$ is assigned to a crystalline transition and in the second cooling, the reversibility of this event is seen (exothermic event at $164^{\circ} \mathrm{C}$ ). In the third heating cycle (Fig. 5c) an event with two overlapped endothermic peaks (195 and $202^{\circ} \mathrm{C}$ ) is observed and in the cooling, the reversibility of one of these events occurs (exothermic event at $138^{\circ} \mathrm{C}$ ) followed by a glass transition at $76^{\circ} \mathrm{C}$. In the fourth heating cycle (Fig. $5 \mathrm{~d}$ ) the reversibility of the glass transition is seen (at $75^{\circ} \mathrm{C}$ ), followed by an exothermic event at $162^{\circ} \mathrm{C}$, assigned to the reversibility of the other overlapped event of the previous heating cycle and finally, it is observed again the endothermic peaks at 195 and $202^{\circ} \mathrm{C}$.

These events were analyzed together to X-ray powder diffractogram in different temperatures (Fig. 4) and confirms the assignment of the events as crystalline transitions.

Correlating the cyclic DSC data with the temperature dependent X-ray powder diffractograms we suggest that the [ $\left.\mathrm{La}(\mathrm{Nap})_{3}\left(\mathrm{H}_{2} \mathrm{O}\right)\right]$ complex has five temperature dependent polymorphic forms. The form I, obtained during synthesis (Fig. 4a), is converted to form II after the dehydration (Fig. 4b). The form II becomes form III at $171^{\circ} \mathrm{C}$ (Fig. 4c). The form IV is obtained by the heating of the previous forms until $195^{\circ} \mathrm{C}$ (Fig. 4d), which is converted to form V at $202^{\circ} \mathrm{C}$ (Fig. 4e). By the cooling of the form $\mathrm{V}$ is possible to return to the form IV.

\subsection{Vibrational spectroscopy}

MIR data of naproxen sodium salt and lanthanum complex (experimental and theoretical) are shown in Table S2 (see Supplementary material) and Fig. 6 . The bands attributed to the carboxylate group for naproxen sodium salt are centered at $1585 \mathrm{~cm}^{-1}$ (asymmetric stretching) and $1391 \mathrm{~cm}^{-1}$ (symmetric stretching). For the complex, these bands are centered at 1549 and $1405 \mathrm{~cm}^{-1}$, respectively. The calculated values of $\Delta\left(v_{\text {asymmetric }}-v_{\text {symmetric }}\right)$ for the complex $\left(144 \mathrm{~cm}^{-1}\right)$ show smaller values in comparison with those calculated for the sodium salt $\left(194 \mathrm{~cm}^{-1}\right)$, suggesting that naproxen is coordinated to lanthanum through the carboxylate group as a bidentate chelating ligand [22]. A good correlation were found between the experimental and theoretical bands indicating that the optimized geometry can explain the coordination mode of the complex.

NIR data of the acid form of naproxen, naproxen sodium salt and lanthanum complex are shown in Table S3 and Fig. S3 (see Supplementary material). Spectra of the sodium salt confirms the total deprotonation and the absence of acid contamination. Water bands appears in the sodium salt and complex spectra.

\subsection{Electronic spectroscopy}

Trivalent lanthanum have an $f^{0}$ electronic configuration, i.e., the core electronic structure has filled shells and as a result, no electronic transition appears in the ultraviolet and visible region, since higher energies are required to promote an electron from filled shells [23], therefore, the large bands that appears in the 230-385 nm range of the DR spectra, Fig. S4 (see Supplementary material), is assigned to the ligand $\pi \rightarrow \pi^{*}$ and $n \rightarrow \pi^{*}$ transitions [24].

\subsection{In vitro biological studies}

The results concerning the cytotoxicity are summarized in Fig. 7a. We verified that naproxen (Nap) has cytotoxic effect on the concentrations of 50.0, 25.0 and $12.5 \mathrm{mg} \mathrm{mL}^{-1}$ in comparison to the control cultures (CC). On the other hand, concentrations of 3.12 and $1.56 \mathrm{mg} \mathrm{mL}^{-1}$ of Nap demonstrated higher cell viability than CC. The compound of lanthanide and naproxen (La-Nap) has cytotoxic effect on the concentrations of 50.0 and $25.0 \mathrm{mg} \mathrm{mL}^{-1}$ in comparison to the control cultures (CC). Similarly to Nap, the La-Nap demonstrated higher cell viability than CC in the concentrations of 3.12 and $1.56 \mathrm{mg} \mathrm{mL}^{-1}$. Comparing the cytotoxic activity of Nap and La-Nap we verified that the La-Nap showed lower cytotoxicity activity in comparison to Nap in the concentrations of 12.5 and $6.25 \mathrm{mg} \mathrm{mL}^{-1}$.

The inflammatory activity of the La-Nap was assessed by their capacity to induce the production of pro-inflammatory metabolites such as cytokines and hydrogen peroxide $\left(\mathrm{H}_{2} \mathrm{O}_{2}\right)$. As a positive control of an inflammatory microenvironment, we used LPS, a potent pro-inflammatory inducer present in the cell wall of Gramnegative bacteria. To assess the anti-inflammatory potential of La-Nap, the compound was added in an initial concentration into the LPS-stimulated monocyte cultures. Cultures with La-Nap exhibited higher levels of TNF- $\alpha$ and IL- $1 \beta$ and lower production of IL- 8 compared to Nap treatment (Fig. 7b). This compound did not interfere in the IL-6, IL-10 and IL-12p70 production by LPS-stimulated monocyte cultures. The La-Nap also increased the production of $\mathrm{H}_{2} \mathrm{O}_{2}$ in comparison to Nap (Fig. 7c).

In the present study, we observed that the complex of lanthanide with naproxen (La-Nap) reduced the anti-inflammatory properties of the compound since LPS-stimulated monocytes showed increased levels of TNF- $\alpha$ and IL-1 $\beta$, cytokines known to characterize the inflammatory processes, whose production is 

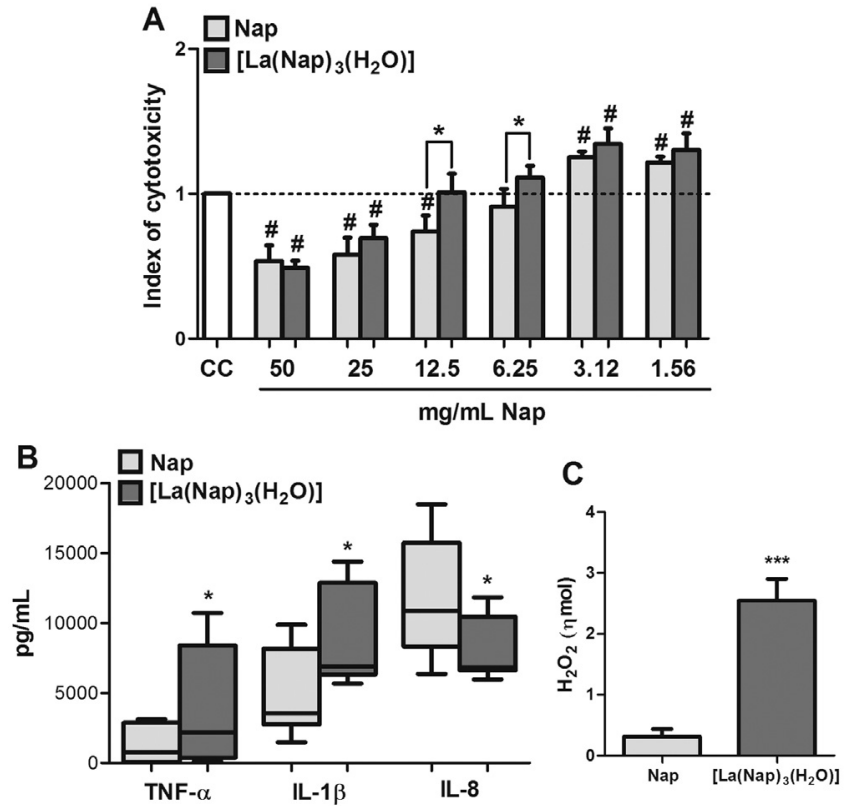

Fig. 7. Biological activities; (a) Index of cytotoxicity. Human PBMCs were stimulated with naproxen (Nap) or lanthanide compound, [ $\mathrm{La}(\mathrm{nap})_{3}\left(\mathrm{H}_{2} \mathrm{O}\right)$ ], in different concentrations and evaluated after $96 \mathrm{~h}$ by MTT assay. The index was expressed using the test-culture: control-culture (CC) ratio. The results are expressed as mean \pm SEM (Standard error of the mean). T-paired test, \#p $<0.05$ (95\% confidence interval) in comparison to CC and ${ }^{*} \mathrm{p}<0.05$ between Nap and [ $\left.\mathrm{La}(\mathrm{nap})_{3}\left(\mathrm{H}_{2} \mathrm{O}\right)\right]$, (b) Cytokine production. LPS-stimulated human monocytes were challenged with Nap or $\left[\mathrm{La}(\mathrm{nap})_{3}\left(\mathrm{H}_{2} \mathrm{O}\right)\right]$ for $24 \mathrm{~h}$. The production of TNF- $\alpha$, IL-1 $\beta$ and IL- 8 was evaluated by CBA kit (flow cytometry). The results are expressed as median, $25-75 \%$ (box), and minimum-maximum (error bars), Wilcoxon test (95\% confidence interval), ${ }^{*} \mathrm{p}<0.05$ between Nap and [ $\left.\mathrm{La}(\mathrm{nap})_{3}\left(\mathrm{H}_{2} \mathrm{O}\right)\right]$, and (c) Production of hydrogen peroxide $\left(\mathrm{H}_{2} \mathrm{O}_{2}\right)$. LPS-stimulated human monocytes were challenged with Nap or [ $\mathrm{La}$ (nap) $)_{3}\left(\mathrm{H}_{2} \mathrm{O}\right)$ ] for $24 \mathrm{~h}$ and the production of $\mathrm{H}_{2} \mathrm{O}_{2}$ was evaluated by phenol red solution (ELISA microreader). The results are expressed as mean $\pm \mathrm{SEM}$. $T$-paired test $\left(95 \%\right.$ confidence interval), ${ }^{* * *} \mathrm{p}<0.001$ between $\mathrm{Nap}$ and $\left[\mathrm{La}(\mathrm{nap})_{3}\left(\mathrm{H}_{2} \mathrm{O}\right)\right]$.

down-regulated by naproxen $[25,26]$. However, we noticed that La-Nap induced decreased production of IL- 8 by these cells. IL8 is a molecule with chemoattractant functions and is released from a variety of cell types during inflammation. This chemokine is responsible for recruitment of inflammatory cells, lymphoid trafficking, wound healing, angiogenesis, and metastasis [27]. Among the diverse biological functions related to IL-8, the exacerbated recruitment of granulocytes into damage tissue could trigger continuous inflammatory response and worsening the host response. In this way, a drug that diminishes the production of IL-8 could be used associated to anti-inflammatory treatments in order to modulate the influx of leucocytes during acute and/or chronic inflammations. For instance, HuMab $10 \mathrm{~F} 8$ is a monoclonal antibody that interrupt the IL-8-dependent human neutrophil activation and migration [28]. However, the cost for production and safety issues represent important factors to discouraging its uses. Thus, La-Na is an interesting option for further studies that involves drugs that interferes in the trafficking of inflammatory cells.

\section{Conclusions}

Based on the TG curves, elemental analysis and the result of complexometric titration, the general formula $\left[\mathrm{La}(\mathrm{nap})_{3}\left(\mathrm{H}_{2} \mathrm{O}\right)\right]$ could be established. The TG curve showed that dehydration occurs in single step and the anhydrous complex is stable until $227^{\circ} \mathrm{C}$. The TG-DTA, DSC and X-ray powder diffraction provided unreported information concerning the thermal behavior and thermal decomposition of this complex and shows that the complex exhibit five temperature dependent polymorphic forms.
The MIR data suggests that naproxen is coordinated to lanthanum through the carboxylate group as a bidentate chelating ligand. Near infrared region data confirms the absence of acid contamination in the sodium salt and in the complex. Absorptions in the UV region are due to ligand $\pi \rightarrow \pi^{*}$ and $n \rightarrow \pi^{*}$ transitions. Theoretical calculations helped in the assignment of the MIR vibrational bands and in the understanding of the coordination mode of the ligands. The coordination polyhedral obtained from the theoretical calculations reveals that the ligands are arranged around the ion with a trigonal prism geometry, distorted by the presence of the coordinated water molecule.

The $\left[\mathrm{La}(\mathrm{Nap})_{3}\left(\mathrm{H}_{2} \mathrm{O}\right)\right]$ complex showed lower cell cytotoxicity in comparison to naproxen and increased the production of pro-inflammatory metabolites, such as TNF- $\alpha$, IL- $1 \beta$ and $\mathrm{H}_{2} \mathrm{O}_{2}$. Nevertheless, the compound decreased IL-8, an important cytokine that interferes in the trafficking of inflammatory cells, and could be interesting to anti-inflammatory treatments in order to modulate the influx of leucocytes.

\section{Acknowledgements}

The authors would like to thank the FAPESP (Procs. 2012/214501 and 2013/09022-7) and CNPq foundations (Brazil) for their financial support. This research was supported by resources supplied by the Center for Scientific Computing (NCC/GridUNESP) of the Sao Paulo State University (UNESP).

\section{Appendix A. Supplementary data}

Supplementary data associated with this article can be found, in the online version, at http://dx.doi.org/10.1016/j.tca.2016.10.007.

\section{References}

[1] D.A. Gálico, B.B. Holanda, G.L. Perpétuo, E. Schnitzler, O. Treu-Filho, G. Bannach, Thermal and spectroscopic studies on solid Ketoprofen of lighter trivalent lanthanides, J. Therm. Anal. Calorim. 108 (2012) 371-379.

[2] D.A. Gálico, R.B. Guerra, G.L. Perpétuo, L.S. Santos, E. Schnitzler, G. Bannach, Thermal studies on solid Ketoprofen of heavier trivalent lanthanides and yttrium (III), Braz. J. Therm. Anal. 1 (2012) 42-47.

[3] D.A. Gálico, M.G. Lahoud, M.R. Davolos, R.C.G. Frem, T.F.C. Fraga-Silva, J Venturini, M.S.P. Arruda, G. Bannach, Spectroscopic: luminescence and in vitro biological studies of solid ketoprofen of heavier trivalent lanthanides and yttrium(III), J. Inorg. Biochem. 140 (2014) 160-166.

[4] M.G. Lahoud, R.C.G. Frem, D.A. Gálico, G. Bannach, M.M. Nolasco, R.A.S. Ferreira, L.D. Carlos, Intriguing light-emission features of ketoprofen-based $\mathrm{Eu}(\mathrm{III})$ adduct due to a strong electron-phonon coupling, J. Lumin. 170 (2016) 357-363.

[5] D.A. Gálico, B.B.C. Holanda, R.B. Guerra, A.O. Legendre, D. Rinaldo, O. Treu-Filho, G. Bannach, Thermal and spectroscopic studies on solid ibuprofen complexes of lighter trivalent lanthanides, Thermochim. Acta 575 (2014) $226-232$.

[6] R.B. Guerra, D.A. Gálico, B.B.C. Holanda, O. Treu-Filho, A.O. Legendre, G. Bannach, New complexes of lighter trivalent with indometacin anti-inflammatory drug-synthesis, thermal properties and spectroscopic study in the solid state, Braz. J. Therm. Anal. 4 (2015) 13-20.

[7] F.X. Campos, A.L.C.S. Nascimento, T.A.D. Colman, D.A. Gálico, O. Treu-Filho, F.J. Caires, A.B. Siqueira, M. Ionashiro, Synthesis, characterization and thermal behavior of solid state of some mefenamate of trivalent lanthanides ( $\mathrm{La} \mathrm{Ce}$, Pr and Nd), J. Therm. Anal. Calorim. 123 (2016) 91-103.

[8] G. Bannach, R. Arcaro, D.C. Ferroni, A.B. Siqueira, O. Treu-Filho, M. Ionashiro, E. Schnitzler, Thermoanalytical study of some anti-inflammatory analgesic agents, J. Therm. Anal. Calorim. 102 (2010) 163-170.

[9] Z.N. Chen, R.W. Deng, J.G. Wu, Synthesis: characterization and antiinflammatory activity of naproxen complexes with rare earth (III), J. Inorg. Biochem. 47 (1992) 81-87.

[10] J.A. Teixeira, W.D.G. Nunes, T.A.D. Colman, A.L.C.S. do Nascimento, F.J. Caires, F.X. Campos, D.A. Gálico, M. Ionashiro, Thermal and spectroscopic study to investigate p-aminobenzoic acid: sodium p-aminobenzoate and its compounds with some ligther trivalente lanthanides, Thermochim. Acta 624 (2016) 59-68.

[11] R.A. Fugita, D.A. Gálico, R.B. Guerra, G.L. Perpétuo, O. Treu-Filho, M.S. Galhiane, R.A. Mendes, G. Bannach, Thermal behaviour of Curcumin, Braz. J. Therm. Anal. 1 (2012) 19-23. 
[12] D.A. Gálico, G.L. Perpétuo, R.A.E. Castro, O. Treu-Filho, A.O. Legendre, M.S. Galhiane, G. Bannach, Thermoanalytical study of nimesulide and their recrystallization products obtained from solutions of several alcohols, J. Therm. Anal. Calorim. 115 (2014) 2385-2390.

[13] H.S. Neto, C. Novak, J.R. Matos, Thermal analysis and compatibility studies of prednicarbate with excipients used in semi solid pharmaceutical form, J. Therm. Anal. Calorim. 97 (2009) 367-374.

[14] D. Giron, S. Monnier, M. Mutz, P. Piechon, T. Buser, F. Stowasser, K. Schulze, M. Bellus, Comparison of quantitative methods for analysis of polyphasic pharmaceuticals, J. Therm. Anal. Calorim. 89 (2007) 729-743.

[15] B. Tiţa, E. Marian, A. Fuliaş, T. Jurca, D. Tiţa, Thermal stability of piroxicam Part 2. Kinetic study of the active substance under isothermal conditions, J. Therm. Anal. Calorim. 112 (2013) 367-374.

[16] A.C.M. Silva, D.A. Gálico, R.B. Guerra, G.L. Perpétuo, A.O. Legendre, D. Rinaldo, G. Bannach, Thermal stability and thermal decomposition of the antihypertensive drug amlodipine besylate, J. Therm. Anal. Calorim. 120 (2015) 889-892.

[17] D. Giron, Applications of thermal analysis and coupled techniques in pharmaceutical industry, J. Therm. Anal. Calorim. 68 (2002) 335-357.

[18] H.A. Flaschka, EDTA Titrations, Pergamon Press, Oxford, 1964.

[19] T. Mosmann, Rapid colorimetric assay for cellular growth and survival: application to proliferation and cytotoxicity assays, J. Immunol. Methods 65 (1983) 55-63.

[20] M. Russo, H.C. Teixeira, M.C. Marcondes, J.A. Barbuto,

Superoxide-independent hydrogen peroxide release by activated macrophages, Braz. J. Med. Biol. Res. 22 (1989) 1271-1273.
[21] A.N. Shirsat, M. Ali, K.N.G. Kaimal, S.R. Bharadwaj, D. Das, Thermochemistry of $\mathrm{La}_{2} \mathrm{O}_{2} \mathrm{CO}_{3}$ decomposition, Thermochim. Acta 399 (2003) 167-170.

[22] G.B. Deacon, R.J. Phillips, Relationships between the carbon?oxygen stretching frequencies of carboxylato complexes and the type of carboxylate coordination, Coord. Chem. Rev. 33 (1980) 227-250.

[23] V.S. Sastri, J.-C.G. Bünzli, V.R. Rao, G.V.S. Rayudu, J.R. Perumareddi, Modern Aspects of Rare Earths and Their Complexes, Elsevier, Amsterdam, 2003.

[24] D.A. Gálico, C.V. Nova, R.B. Guerra, G. Bannach, Synthesis, thermal and spectroscopic studies of a new lithium salt of naproxen, Braz. J. Therm. Anal. 4 (2015) 39-43.

[25] L.C. Salgado, Z.F. Martínez, S.G. Alarcón, C.S. Martínez, Effect of naproxen sodium on serum concentrations of IL-1 IL-6, and TNF in patients with acute, purulent pharyngo-tonsillitis, Rev. Alerg. Mex. 46 (1999) 78-82.

[26] C.S. Martínez, L.C. Salgado, Z.F. Martínez, Effect of naproxen on serum concentrations of IL-I IL-6, and TNF in patients with osteoarthritis, Rev. Alerg. Mex. 48 (2001) 119-122.

[27] B.S. Qazi, K. Tang, A. Qazi, Recent advances in underlying pathologies provide insight into interleukin-8 expression-mediated inflammation and angiogenesis, Int. J. Inflamm. 2011 (2011) 908468.

[28] L. Skov, F.J. Beurskens, C.O. Zachariae, S. Reitamo, J. Teeling, D. Satijn, K.M. Knudsen, E.P. Boot, D. Hudson, O. Baadsgaard, P.W. Parren, J.G. van de Winkel, IL-8 as antibody therapeutic target in inflammatory diseases: reduction of clinical activity in palmoplantarpustulosis, J. Immunol. 181 (2008) 669-679. 